\title{
Able-Bodied Individuals' Initial Interaction Decisions Concerning a Partner in a Wheelchair
}

\author{
${ }^{1}$ Melissa Ann Tafoya and ${ }^{2}$ Paul Mongeau \\ ${ }^{I}$ Department of Communication Studies, La Sierra University, Riverside, CA, USA \\ ${ }^{2}$ Hugh Downs School of Human Communication, Arizona State University, Tempe, AZ, USA
}

Article history

Received: 12-10-2018

Revised: 23-10-2018

Accepted: 03-12-2018

Corresponding Author:

Melissa A. Tafoya

La Sierra University, Riverside,

CA, USA

Tel.: +1-831-656-3954

Email:mtafoya@lasierra.edu

\begin{abstract}
Establishing and maintaining personal relationships is a quintessential part of the human experience, with a few notable exceptions, persons with disabilities have been virtually ignored by relationships scholars. This study seeks to advance disability research by examining how a wheelchair influences able-bodied participant's perceptions of initial interactions. Using various scenarios, we asked students how they would react if they were at a bar and someone in a wheelchair showed an interest in them. Overall, men reacted more negatively than women (i.e., avoidance, sex goals, interest, homophily, etc.) at the thought of approaching someone in a wheelchair. We have an ethical obligation to break down these barriers and assumptions made by able- bodied individuals, especially since the quality of an individual's relationships represents an important component of their quality of life.
\end{abstract}

Keywords: Disability, Dating, Interpersonal Communication, Initial Interactions, Health Communication, Social Psychology

\section{Introduction}

Throughout the life course, interpersonal relationships play a significant role in nearly every domain of human existence (Reis and Collins, 2004). Very few features of the environment are more influential to emotional, cognitive and physical development than the ability to develop close interpersonal relationships (Dickson et al., 2005). Developing and maintaining close relationships and the quality of interpersonal relationships contribute to one's physical health, psychological well-being and overall quality of life (Leone and Hawkins, 2006). Interpersonal relationships are "the foundation and theme of human life" (Reis et al., 2000, p.844).

It is not surprising that researchers from a number of disciplines have given considerable attention to understanding the nature and dynamics of interpersonal relationships (Leone and Hawkins, 2006). Few factors are more influential to an individual's development than the ability to develop close relationships. Even in the best of circumstances, forming and maintaining close interpersonal relationships can be a challenge (Braithwaite and Harter, 2000). Everyone faces challenges and difficulties in developing interpersonal relationships (Mongeau et al., 2006). The nature of the unique challenges and barriers faced, however, differs dramatically across people. The challenges faced by one person may not be the same, or similar to the challenges faced by another person. We could go so far as to claim that the unique set of challenges a person faces largely determines his or her life circumstances (Gordon et al., 2004; Mongeau et al., 2006).

For some individuals, physical and social barriers pose significant challenges in forming romantic relationships. Specifically, when compared with their able-bodied counterparts, people with visible physical disabilities likely experience greater challenges, more difficulty and additional barriers when establishing personal relationships (Rintala et al., 1997). One important source of these barriers lies on the social stereotypes and attitudes of able- bodied individuals. Therefore, the primary goal of this investigation is to continue a recent conversation on the relational challenges faced by people with disabilities. Specifically, this study will focus on the role of disability (as indicated by the presence of a wheelchair) on able-bodied individuals' initial interaction decisions. 


\section{Relational Challenges Facing People with Disabilities}

People with disabilities encounter several personal, social and environmental barriers that make it difficult to establish and/or maintain intimate relationships (Braithwaite and Harter, 2000; Rintala et al., 1997). Compared to able-bodied individuals, people with disabilities have a harder time meeting potential partners and forming intimate relationships (Stevens et al., 1996). According to Milligan and Neufeldt (2001), people with disabilities are "significantly disadvantaged in the pursuit of satisfying relationships," particularly romantic and sexual relationships (p. 98). Having a disability can add yet another facet of complexity to developing relationships, thereby making the process even more difficult (Gordon et al., 2004).

\section{Able-Bodied Individuals' Views of People with Disabilities}

There is little disagreement in the disability research that the social and psychological problems faced by people with disabilities are equal to physical problems if they don't exceed (Fine and Asch, 1988). An important source of the difficulties faced by people with disabilities lies in negative attitudes held by able- bodied individuals (Hergenrather and Rhodes, 2007). People with disabilities face social barriers of discrimination, marginality, a lack of social acceptance and social rejection (Fine \& Asch). People with disabilities have been historically isolated from the rest of society (Crawford and Ostrove, 2003). The stigmatizing effect of disability has barely changed in the past 30 years (Fichten et al., 2005) and influences public opinion. This has lead able- bodied individuals to have negative attitudes, reduced social acceptance, decreased comfort levels, increased avoidance behaviors and/or rejection of people with disabilities (Goldstein and Johnson, 1997; Milligan and Neufeldt, 2001).

The overall life experiences and social opportunities of people with disabilities are significantly affected by societal attitudes (Chen et al., 2002). Therefore, studying the attitudes toward people with disabilities is essential. Able-bodied individuals' negative attitudes serve as invisible barriers that inhibit people with disabilities' ability to pursue personal and social opportunities (Hergenrather and Rhodes, 2007). For instance, Crawford and Ostrove (2003) found that women with disabilities reported that, to some extent, their ability to access meaningful social interactions was limited by their disabilities, or others' attitudes towards them.

According to Tepper (2005), the problem for relationships of people with disabilities has more to do with able-bodied individuals avoiding intimate relationships with people with disabilities than the other way around. Regardless of the nature of the disability, able-bodied people are often uncomfortable with people with disabilities because of negative attitudes, faulty assumptions and stereotyped characterizations of people with disabilities (Fichten et al., 2005). Moreover, Fichten et al. (1989) found that able-bodied young adults believed that young adults with disabilities were uncomfortable about dating, dated less frequently, more likely to date other people with disabilities and were socially anxious.

The most common assumption about people with disabilities is that they are asexual (Tepper, 2005). Research has shown that the interactions and communication between people who have a disability and those who do not are fraught with difficulties, at least initially (Fichten et al., 1985; Braithwaite and Thompson, 2000). These interactions tend to be filled with high levels of uncertainty and discomfort. In general, able-bodied people tend to avoid these situations altogether (Braithwaite and Thompson, 2000).

\section{Study Overview and Hypotheses}

Since every relationship must begin with an initial interaction, the focus of the current study is people's perceptions of initial interactions with someone who is disabled. Given the lack of research on able-bodied individuals' specific views of people with disabilities, we chose to perform a scenario study that varied the There are a large number of disabilities, creating a number of unique challenges. Therefore, rather than describe a specific disability (e.g., spinal cord injury or spin bifida), we chose to describe a person as being a wheelchair. In this study, participants read one of eight initial-interaction scenarios. We varied disability status (able-bodied or in a wheelchair), activity (playing pool or sitting) and attractiveness level (highly attractive or no mention of attractiveness) varied across scenarios (see Appendix).

\section{Initial Interactions with People with Disabilities}

Every relationship starts with an initial encounter (Leone and Hawkins, 2006). The purpose of the current study is to explore how a disability influences people's perceptions of initial interactions. One reason why ablebodied individuals might experience uncertainty when interacting with people with disabilities is that they have little experience in doing so (Barnes and Mercer, 2005). Being in a wheelchair, in and of itself, does not generate much information concerning what a person can, or cannot, do. What a person does in the wheelchair, however, can be quite informative. It is also likely that able-bodied individuals have very little experience interacting with a person with a disability in quasiromantic interactions, such as initial interactions in a bar. Given the negative attitudes and expectations held by able-bodied individuals toward people with disabilities, we pose the following hypotheses: 
Hypothesis 1: Able-bodied individuals will be less likely to approach a person of the opposite sex when that other is described as being in a wheelchair.

Hypothesis 2: Able-bodied individuals will be more likely to avoid initial interactions when the person is described as being in a wheelchair.

Hypothesis 3: Able bodied individuals will be more likely to 'indirect approach' (i.e., indirectly approach so as to facilitate interaction) when the target is not described as being in a wheelchair. Hypothesis 4: Attempts to reduce uncertainty about the conversational partner will be more prevalent when the target is able-bodied, when compared to being in a wheelchair.

Hypothesis 5: When engaged in conversation, able- bodied individuals will express less interest in the person described as being in a wheelchair.

Being in a wheelchair, in and of itself, does not generate much information concerning what a person can, or cannot, do. What a person does in the wheelchair, however, can be quite informative. How actively involved an individual is may reduce uncertainty by providing considerable information about what the individual in the wheelchair might be able to perform. It is not clear how a target person's physical activity might influence approach, interaction and other decisions. Therefore, we pose a research question.

Research Question 1: How will the target's physical activity (e.g., playing pool versus sitting quietly in the bar) influence approach, interaction and relational decision making?

Initial interactions in quasi-romantic settings such as bars where both parties consume alcohol likely generate some hint of sexual interaction between partners. The alleged "hookup culture" on college campuses generally fits the description where partners meet at a bar, consume alcohol together and subsequently engage in some degree of sexual interaction (e.g., Paul and Hayes, 2002; Stepp, 2007). Given the generalized view that people with disabilities are 'asexual' (Milligan and Neufeldt, 2001; Chance, 2002; Braithwaite and Thompson, 2000) we propose a sixth hypothesis.

Hypothesis 6a. Able-bodied individuals will express less sexual intent when the person described as being in a wheelchair.

There is also likely a sex difference in sexual intent in the interaction. Men generally consider sexual interaction to be a more important goal in early relational stages than do women (e.g., Clark et al., 1999; Mongeau et al., 2004; Roscoe et al., 1987).

Hypothesis 6b. Men will express less sexual intent when than women.
Given the logic leading to the previous two hypotheses, we also predict a sex of participant by ablebodied/wheelchair interaction. Specifically, we expect that the partner being in a wheelchair will influence men's sexual intent to a greater extent than women. Women generally do not report sexual interest in initial interactions, so their reports should be less influenced by the presence or absence of a wheelchair. Therefore, we pose our final hypothesis.

Hypothesis 6c. Whether the conversational partner is in a wheelchair will influence men's reports of sexual intent to a greater extent than it will women's accounts

One of the potential explanatory mechanisms for the negative influence of disability on able-bodied individual's is similarity. Similarity relates positively to both attraction and liking (Fichten et al., 1989) and the effect on liking is much stronger when partners are strangers or have interacted only briefly (I've got a citation for this...I'll fill it in or send it later). Moreover, there is a positive relationship between similarity and attraction (Barelds and Barelds-Dijkstra,

2007). Therefore, we pose our next hypothesis.

Hypothesis7: Participants will judge the conversational partner as less similar when he/she is described as being in a wheelchair.

A potential theoretical explanation for the effects of disability on initial interactions comes from predicted outcome value (i.e., POV) theory (Sunnafrank, 1986). Sunnafrank (1986) suggests that like other relational development theories (e.g., Thibaut and Kellley, 1959; Altman and Taylor, 1973), individuals choose relationships and relationship partners that will maximize outcome values (i.e., rewards in relation to costs). Given the greater uncertainty concerning interacting with a person with a disability, it is less likely that participants would be able to make, or make very positive, predicted outcome value judgments.

\section{Method}

\section{Participants}

Participants $(N=214)$ were $82(38.3 \%)$ men and 130 $(60.7 \%)$ women undergraduates from a large southwestern university (2 participants did not report their sex). Participants ranged in age from 18 to 52 years $(M=22.58$ years, $S D=4.50$ years $)$. Most $(80.4 \%)$ were Caucasian, whereas $8.4 \%$ were Hispanic, $2.3 \%$ were African-American, $4.7 \%$ were Asian and $4.2 \%$ were of other ethnic origins. At the time of the study, $4.7 \%$ were freshman, $15 \%$ were sophomores, $41.6 \%$ were juniors, $34.6 \%$ were seniors and $2.8 \%$ were graduate students in college. 


\section{Procedure}

Undergraduate and graduate college students were recruited from a large southwestern university in compliance with the institution's human subjects Institutional Review Board (IRB). Participants were asked to read a scenario about an initial interaction in a bar. Participants were asked to take the place of the target person in the scenario. Participants were asked to take the target's position even if they were dating another individual exclusively. Following the scenario, participants completed a series of scales, some of which are described below.

\section{Design}

This study utilized a 2 (wheelchair or able-bodied) by 2 (extremely attractive or no mention of attractiveness) by 2 (activity: sitting alone or playing pool) factorial design. All independent variables were manipulated in scenarios. The scenario presented the participant as walking into a neighborhood bar and orders something to drink. The participant is waiting for their drink and described as scanning the room, noticing that another person (the target) is "eyeing" you (i.e., he/she appears to be looking at you with interest)." The attractiveness manipulation was performed by describing the target as either "extremely attractive" or not making any mention of physical appearance. The able boded/wheelchair manipulation was performed by describing the person as sitting behind the pool table. In the able-bodied condition, no other physical description of the target person is made, however, in the wheelchair condition, the scenario indicates, "you notice that they are not in a chair, but in a wheelchair" (emphasis in scenarios). The activity manipulation describes the target person as either playing pool and holding a drink (activity condition) or simply holding a drink (no activity condition). Please see Appendix for specific scenarios.

\section{Instrumentation}

\section{Initial Interaction Goals}

The initial interaction and approach decision was measured using terms developed for this investigation. Forty-two items were developed that focused on the initial approach decisions, conversation starter, conversational topics during an initial interaction, interest in subsequent interactions and sex goals. Participants responded on 1 (strongly disagree) to 7 (strongly agree) Likert-type items.

A principal component analysis with Varimax rotation was conducted to identify underlying factors. Inspection of the factor matrixes suggested that a 6factor solution best fit the data. The resulting 6-factor solution (containing 27 of the original 42 items) accounted for $68.6 \%$ of the variance.
The first factor, labeled sex goals, consisted of six items $(\alpha=0.96)$ that assessed the participants' desire to engage in sexual activity during the initial interaction (e.g., "I would try to kiss him/her", "I would see if he/she was interested in having sex"). The second factor was termed avoidance, which included six items $(\alpha=0.92)$ describing behaviors designed to eliminate the chance of interacting with the target (e.g., "I would try to avoid looking at him/her", “... avoid going near him/her"). The third factor was labeled approach and consisted of 5items $(\alpha=0.92)$ revolved around increasing the probability of interacting with the target (e.g., "I would try to approach him/her", “...stand near him/her"). Factor four was labeled uncertainty reduction because of its loading on 3 -items $(\alpha=0.87)$ on behaviors designed to learn more about the other person (e.g., I would try to understand who he/she was as a person", "...try to get to know him/her"). The fifth factor loaded 3-items ( $\alpha=$ 0.81 ) focused on interest in a second meeting with the other person (e.g., "I would ask him/her out to dinner", "... ask him/her if we could meet for lunch"). The final factor, indirect approach, included 3-items $(\alpha=0.79)$ that described physically moving closer to the other person devoid of actual communication, indicating attempts to indirectly approach (e.g., "I would try to move toward the pool tables", “... stand next to him/her").

Finally, participants were asked to assess the degree of similarity they shared with the target. Similarity was measured with the homophily subscale of a modified version of scales from McCroskey et al. (2006). The items represented general statements about judgments of similarity (e.g., "This person's experiences are similar to mine", "This person has a lot in common with me"). Chronbach's alpha were acceptable for similarity $(\alpha=0.83)$.

\section{Results}

Given this study's factorial design, a series of fourway ANOVAs were performed with sex of the participant, target' activity level, target' disability status and target' attractiveness as the independent variables. The sixinteraction goals were used as the dependent variable.

Hypothesis 1 predicted that there would be a main effect for disability on judgments of willingness to approach the target. Specifically, we predicted that participants would report being more likely to approach the able-bodied target when compared with the target in a wheelchair. Results were not strictly consistent with this prediction. Instead, for approach tactics, there was a significant main effect for participants sex, $F(1,195)=$ $16.84, p<0.001$, partial $\eta^{2}=0.08$. Men would reportedly approach the target more $(M=3.99, \mathrm{SD}=1.61)$ than women $(M=3.27, S D=1.22)$. Along the lines of our hypothesis, the main effect of participant' sex should be considered in light of a sex of participant by disability status interaction, $F(1,195)=6.42, p=0.01$, partial $\eta^{2}=$ 0.03 . Men and women are more likely to approach an 
able-bodied individual $(M=4.75, S D=1.44 ; M=3.50$, $S D=1.13)$ than disabled $(M=3.40, S D=1.49 ; M=$ $3.04, S D=1.27$ ), respectively. The main effect for disability was significant. Disability status influences men's decision to approach to a much higher degree than it does for women. Therefore, hypothesis 1 was consistent with the data only for male participants.

Hypothesis 2 predicted that participants would report avoiding targets in a wheelchair to a greater extent than an able-bodied target. Data are consistent with this prediction as only a main effect for disability reached significance, $F(1,195)=24.56, \mathrm{p}<0.001$, partial $\eta^{2}=$ 0.11. Participants reported that they would be more likely to avoid a person was in a wheelchair $(M=3.34$, $S D=1.48)$ when compared to able-bodied individual $(M$ $=2.44, S D=1.17$ ).

Hypothesis 3 predicted that disability status would influence indirect approach behaviors (i.e., moving toward, but not opening interaction with the target). Only the main effect for disability status reached significance, $F(1,195)=33.77, p<0.001$, partial $\eta^{2}=0.15$. Contrary to our hypothesis, however, when the target was in a wheelchair, participants were much more likely to indirectly approach $(M=4.63, S D=1.27)$ than if the other person was able-bodied $(M=3.55, S D=1.44)$.

Hypothesis 4 predicated a main effect for disability status on willingness to reduce uncertainty about the target. Consistent with this prediction, a significant main effect for disability status indicated that participants reported more motivation to reduce uncertainty when the individual is able-bodied $(M=5.02, S D=1.15)$ than in a wheelchair $(M=4.43, S D=1.46), F(1,195)=10.84, p$ $=0.001$, partial $\eta^{2}=0.05$.

The main effect for disability status is qualified by a disability status by attractiveness interaction, $F(1,195)$ $=4.00, p<0.05$, partial $\eta^{2}=0.02$. Attractiveness influences uncertainty reduction motivation only when the target is in a wheelchair. Specifically, for able-bodied targets, uncertainty reduction attempts did not differ by attractiveness (attractive $M=5.01, S D=1.20$; no mention $M=5.02, S D=1.10)$. When the target was described as being in a wheelchair, however, uncertainty reduction tactics were advocated more strongly when the target was described as highly attractive $(M=4.60, S D=$ 1.54) compared with when attractiveness was not mentioned $(M=4.21, S D=1.33)$. Furthermore, a significant activity level by attractiveness interaction was found for uncertainty reduction, $F(1,195)=7.37$, $p<0.01$, partial $\eta^{2}=0.04$.

Participants reported higher uncertainty reduction behaviors when the target sitting down was described as highly attractive $(M=5.22, S D=1.08)$ compared unstated attractiveness levels $(M=4.53, S D=1.21)$. Though not as robust, the opposite was true when the other person was playing pool. Means for uncertainty reduction tactics were lower for highly attractive individuals $(M=4.49, S D=1.54)$ than when attractiveness level us unknown $(M=4.71, S D=1.36)$.

Finally, the target's activity level interacted with participant sex to influence uncertainty reduction tactics, $F(1,195)=3.89, p=0.05$, partial $\eta^{2}=0.02$. Men were more motivated to reduce uncertainty when the target is playing pool $(M=4.70, S D=1.57)$ than if they are sitting down $(M=4.59, S D=1.27)$. The opposite is true for women, with uncertainty reduction tactics decreasing if the individual is playing pool $(M=4.51, S D=1.40)$ rather than just sitting down $(M=4.99, S D=1.12)$.

Hypothesis 5 predicted a man effect of disability status on judgments of interest in future interaction. Again, data were not strictly consistent with this prediction. A significant main effect for sex indicated, not surprisingly, that men are more likely to express interest by asking for a second meeting $(M=3.58, S D=$ 1.56) than were women $M=2.76, S D=1.20, F(1,193)$ $=19.59, p<0.001$, partial $\eta^{2}=0.09$.

The main effect for sex on interest in future interaction, however, is qualified by a significant interaction between participant' sex and disability status, $F(1,193)=8.72, p=0.004$, partial $\eta^{2}=0.04$. The main effect for sex is considerably more pronounced when the target is able-bodied (male $M=4.10, S D=1.50$; female $M$ $=2.67, S D=1.25$ ) than when the target is described as being in a wheelchair (male $M=3.19, S D=1.51$; female $M=2.84, S D=1.15$ ). Partially consistent with Hypothesis 4 , disability status exerted a strong influence on men's, but not women's, expressions of interest in future interaction.

Hypothesis 6 predicted a main effect for disability status (6a), a main effect for sex of participant (6b) and a disability status by disability status interaction (6c). Data are consistent with all three parts of this hypothesis. Consistent with hypothesis $6 \mathrm{a}$, there was a main effect for disability on sexual goals, $F(1,193)=3.87, p=0.05$, partial $\eta^{2}=0.02$. Participants rated sex goals higher when the other person was able-bodied $(M=2.02, S D=1.36)$ versus in a wheelchair $(M=1.84, S D=1.43)$. Consistent with hypothesis $6 \mathrm{~b}$, there was a significant main effect for participant' sex indicated that men rated sex goals higher $(M$ $=2.63, S D=1.74)$ than did women $(M=1.49, S D=0.88)$, $F(1,193)=42.56, p<0.001$, partial $\eta^{2}=0.18$.

The main effects, however, are qualified by a significant two-way interaction between disability status and participant sex, $F(1,193)=5.63, p<0.02$, partial $\eta^{2}=$ 0.03 . Consistent with hypothesis $6 \mathrm{c}$, the main effect for disability appeared for men (able bodied $M=3.09, S D=$ 1.63; wheelchair $M=2.28, S D=1.76$ ) but not for women (wheelchair $M=1.53, S D=1.04$; able-bodied $M$ $=1.45, S D=0.70)$. Put another way, the sex differences in sexual activity goals are twice as large in the ablebodied, when compared to the wheelchair, condition.

Hypothesis 7 predicted that there would be a main effect of disability status on judgments of similarity. 
Consistent with this prediction, a significant main effect appeared for disability status, $F(1,194=24.04, p<0.001$, partial $\eta^{2}=0.11$. Participants judged the able-bodied target as more similar to themselves $(M=4.52, S D=$ 0.82 ) when compared with the target described as being in a wheelchair $(M=3.86, S D=0.98)$. No other main effects or interactions were significant.

\section{Discussion}

Individuals with disabilities, whether physical, emotional, learning, or cognitive, represent a large and ever-growing portion of the US population (U.S. Census Bureau, 2000). Individuals with visible physical disabilities face a number of barriers that interfere with their ability to initiate, develop and maintain close romantic relationships (Braithwaite and Harter, 2000; Rintala et al., 1997). The processes that lead to the eventual development of romantic relationships are difficult enough under the best of circumstances. They become more complex when one partner has a visible physical disability (Gordon et al., 2004).

Several studies have investigated relationship processes from the perspective of the disabled individuals (e.g., Crawford and Ostrove, 2003). These reports clearly indicate that able-bodied have a prejudiced view when it comes to interacting and forming interactions with disabled individuals. Relatively few studies, however, have investigated relationships between able-bodied individuals and disabled individuals from the perspective of the ablebodied. As a consequence, the primary goal of this study was to investigating able-bodied individuals' social stereotypes concerning interacting and forming early relationships with people with disabilities. We chose to view these stereotypes by investigating the decisions and evaluations made by able-bodied individuals when faced with an initial interaction situation in a quasi-romantic context (i.e., a bar).

Results from this investigation clearly highlight the challenges faced by individuals with disabilities when it comes to meeting, interacting and forming sexual and/or romantic relationships with partners. The clearest and most consistent result was that able- bodied individuals were more likely to engage in interaction with an ablebodied partner when compared with a target individual described as being in a wheelchair. Specifically, disability status (specifically, whether or not the target was described as being in a wheelchair) significantly influenced participants' judgments of avoiding the partner, interest in reducing uncertainty in a target, indirect approach behaviors, sexual motivations and judgments of similarity. In all cases except indirect approach (i.e., approaching, but not interacting with, the target), participants were less likely to engage in the behaviors necessary to initiate a relationship (romantic, sexual, or otherwise) with the target in a wheelchair.

There is some evidence that males still take the role of initiator in initial interactions, such as first dates, that might spur romantic or sexual interactions (e.g., Laner and Ventrone, 1998, 200 Pryor and Merluzzi, 1985; Rose and Frieze, 1993). Consistent with this notion, there were significant sex of participant effects on the variables most clearly related to relational and sexual interest. Specifically, men, to a greater extent than women, were more likely to approach, express interest in a subsequent interaction (e.g., date) with the target and have sexual motivations.

These results are consistent large and consistent sex differences in interest in and attitudes toward, sexual activity in the early stages of relationship development (e.g., Oliver and Hyde, 1993; Hyde, 2005). Men tend to be much more interested in and accepting of, sexual interaction outside the bounds of a close committed relationships than are women. Given that the interactions between participant and target would presumably be an initial interaction, our results are consistent with considerable earlier research.

On the other hand, women tend to be less interested in and have somewhat more negative attitudes toward, sexual interaction outside romantic relationships. In short, sexual interactions are less important and of less interest, to women when partners first meet. As a consequence, questions of whether a man in a wheelchair is interested in and/or able to, engaging in sexual interaction is likely a less salient issue for women. Therefore, disability status differences were much smaller for women, when compared with men.

However, the most relevant finding was disability status moderated all three of these sex differences in a consistent manner. Men (when compared with women) reported being more likely to approach, express interest in subsequent interaction and sexual goals only when the target was not described as being in a wheelchair. The disability status effect on approach decisions, sexual motivation and interest in future interaction were substantial for men only.

While our results clearly indicate that visibly disabled individuals are at a disadvantage in early relational contexts, the explanation for this effect remains less than clear. It might be, for example, that able-bodied men consider disabled women to be less interested in sexual activity (when compared with able-bodied women). It is also possible, that able- bodied men would consider women in wheelchairs to be unable to engage in sexual interaction. At the very least, we would expect that able-bodied men to be more uncertain of whether and how, disabled women could or want to engage in sexual interaction.

In comparison to disability status and participants' sex, target's attractiveness and activity levels had much 
more limited influence on dependent variables. In fact, these independent variables influence only attempts to reduce uncertainty and even then, only when interacting with other independent variables. Attractiveness interacted separately with disability status and activity level to influence uncertainty reduction. In the only interaction involving disability status, attractiveness interacted with disability to influence uncertainty reduction as participants reported greater motivation to reduce uncertainty when the target was described as extremely attractive (when compared to when attractiveness was not mentioned). Attractiveness did not influence uncertainty reduction in the able-bodied condition.

It is interesting that the target's activity level did not interact with disability status to influence interaction variables. Our expectation was that the target in a wheelchair's ability to play pool would provide useful information concerning what the individual might or might not be able to do. Our scenarios, however, only indicate that the target was 'holding a pool cue in one hand' rather than providing any indication of the person's skill. In addition, it might be that playing pool with at a bar might be perceived as a social activity (i.e., something done with, or against, other people) such that the participant might not want to initiate contact with someone who is already with someone else.

\section{Limitations and Directions for Future Research}

As with all investigations, this study is not without limitations. One limitation is that we observed no actual interaction between social actors. While observing actual interaction between able-bodied individuals and targets in wheelchairs is important, this study was designed to investigate able-bodied respondents' social attitudes and stereotypes. We consider these attitudes and stereotypes to be considered critical to the effectiveness of social interaction between individuals able-bodied and disabled individuals.

Results from this investigation indicate that able bodied men in particular, are less likely to approach a woman in a wheelchair (when compared with a presumably able-bodied woman) for the purpose of initiating social interaction in a voluntary context. It is less clear, however, what might happen in involuntary (e.g., work or classroom) context.

\section{Conclusion}

The results of the current study have some significant implications for people's perceptions about people with disabilities. In perceptions of initial interactions, participants are reportedly less likely to approach, have sex goals, reduce uncertainty and show interest when the target was disabled. Participant's reported being more likely to avoid and indirectly approach when the target was disabled. Participants also judged the target with a disability as less similar to themselves and less physically attractive. Sex of the participant, physical attractiveness and activity plays a role in people's perceptions as well. This research points to the fact that more research needs to be done and that there are more complex issues going on.

\section{Acknowledgement}

The authors would like to thank Jade Williams for her consultation on in developing this study.

\section{Funding Information}

This research was not funded.

\section{Author's Contributions}

Melissa Tafoya and Paul Mongeau equally contributed to the preparation, development and publication of this manuscript.

\section{Ethics}

There are no ethical issues that may arise from publication of this manuscript.

\section{References}

Altman, I. and D. Taylor, 1973. Social penetration: The development of interpersonal relationships. New York: Holt.

Barelds, D.P.H. and P. Barelds-Dijkstra, 2007. Relations between different types of jealousy and self and partner perceptions of relationship quality. Clinical Psychol. Psychotherapy, 14: 176-188.

DOI: $10.1002 /$ cpp.532

Barnes, C. and G. Mercer, 2005. Disability, work and welfare: Challenging the social exclusion of disabled people. Work, Employment Society, 19: 527-545. DOI: 10.1177/0950017005055669

Braithwaite, D.O. and L. Harter, 2000. Communication and the Management of Dialectical Tensions in the Personal Relationships of People with Disabilities. In: Handbook of Communication and People with Disabilities: Research and Application, D.O. Braithwaite and T.L. Thompson (Eds.), Mahwah, NJ: Erlbaum, pp: 17-36.

Braithwaite, D.O. and T.L. Thompson, 2000. Handbook of communication and people with disabilities: Research and application. Mahwah, NJ: Lawrence Erlbaum Associates.

Chance, R.S., 2002. To love and be loved: Sexuality and people with physical disabilities. J. Psychol. Theology, 30: 195-208. DOI: $10.1177 / 009164710203000303$ 
Chen, C.C.H., T.M.C. Lee, H.K. Yuen and F. Chan, 2002. Attitudes toward people with disabilities between Chinese rehabilitation and business students: An implication for practice. Rehabilitation Psychol., 68: 5-11.

Clark, C.L., P.R. Shaver and M.F. Abrahams, 1999. Strategic behaviors in romantic relationship initiation. Personality Social Psychol. Bull., 25: 7109-722. DOI: 10.1177/0146167299025006006

Crawford, D. and J.M. Ostrove, 2003. Representations of disability and the interpersonal relationships of women with disabilities. Women Therapy, 26: 179-194. DOI: $10.1300 / J 015 \mathrm{v} 26 \mathrm{n} 0301$

Dickson, F.C., P.C. Hughes and K.L. Walker, 2005. An exploratory investigation into dating among laterlife women. Western J. Communication, 69: 67-82.

Fichten, C.S., F. Schipper and N. Cutler, 2005. Does volunteering with children affect attitudes toward adults with disabilities? A prospective study of unequal contact. Rehabilitation Psychol., 50: 164-173. DOI: 10.1037/0090-5550.50.2.164

Fichten, C.S., K. Robillard, D. Judd and R. Amsel, 1989. College students with physical disabilities: Myths and realities. Rehabilitation Psychol., 34: 243-257. DOI: $10.1037 / \mathrm{h} 0091729$

Fichten, C.S., V. Compton and R. Amsel, 1985. Imagined empathy and attributions concerning activity preferences of physically disabled college students. Rehabilitation Psychol., 30: 235-239.

DOI: $10.1037 / \mathrm{h} 0091033$

Fine, M. and A. Asch, 1988. Disability beyond stigma: social interaction, discrimination and activism. J. Social Issues, 44: 3-21. DOI: $10.1111 / \mathrm{j} .1540-4560.1988 . t b 02045$

Goldstein, S.B. and V.A. Johnson, 1997. Stigma by association: Perceptions of the dating partners of college students with physical disabilities. Basic Applied Social Psychol., 19: 495-504. DOI: $10.1207 / \mathrm{s} 15324834$ basp1904_6

Gordon, P.A., M.K. Tschopp and D. Feldman, 2004. Addressing issues of sexuality with adolescents with disabilities. Child Adolescent Social Work J., 21: 513-527.

DOI: 10.1023/B:CASW.0000043362.62986.6f

Hergenrather, K. and S. Rhodes, 2007. Exploring undergraduate student attitudes toward persons with disabilities. Rehabilitation Counseling Bulletin, 50: 66-75. DOI: 10.1177/00343552070500020501

Hyde, J.S., 2005. The gender similarities hypothesis. Am. Psychol., 60: 581-582. DOI: $10.1037 / 0003-066 X .60 .6 .581$

Laner, M.R. and N.A. Vetrone, 1998. Egalitarian daters/Traditionalist dates. J. Family Issues, 19: 468-477. DOI: 10.1177/019251398019004005
Leone, C. and L.B. Hawkins, 2006. Self-monitoring and close relationships. J. Personality, 74: 739-778.

Lyons, R.F., M.J.L. Sullivan, P.G. Ritvo and J.C. Coyne, 1995. Sage series on close relationships. Relationships in chronic illness and disability. Thousand Oaks, CA: Sage Publications.

McCroskey, L.L., J.C. McCroskey and V.P. Richmond, 2006. Analysis and improvement of the measurement of interpersonal attraction and homophily. Communication Quarterly, 54: 1-31.

Milligan, M.S. and A.H. Neufeldt, 2001. The myth of asexuality: A survey of social and empirical evidence. Sex Disability, 19: 91-109.

Mongeau, P.A., J. Williams and M.A. Tafoya, 2006. Challenges facing people with disabilities in initiating romantic relationships: Establishing an agenda. Presented to Western States Communication Association, Palm Springs, CA.

Mongeau, P.A., M.C. Morr Serewicz and L.F. Therrien, 2004. Goals for cross-sex first dates: Identification, measurement and the influence of contextual factors. Communication Monographs, 71: 121-147. DOI: 10.1080/0363775042331302514

Oliver, M. and J. Hyde, 1993. Gender differences in sexuality: A meta-analysis. Psychol. Bull., 114: 29-51.

Paul, E.L. and K.A. Hayes, 2002. The casualties of 'casual' sex: A qualitative exploration of the phenomenology of college students' hookups. J. Social Personal Relationships, 19 639-661. DOI: $10.1177 / 0265407502195006$

Pryor, J.B. and T.V. Merluzzi, 1985. The role of expertise in processing social interaction scripts. J. Experimental Social Psychol., 21: 362-379. DOI: $10.1016 / 0022-1031(85) 90036-8$

Reis, H.T. and W.A. Collins, 2004. Human behavior and psychological science. Current Directions Psychol. Sci., 13: 233-237. DOI: $10.1111 / \mathrm{j} .0963-7214.2004 .00315 . x$

Reis, H.T., W.A. Collins and E. Berscheid, 2000. The relationship context of human behavior and development. Psychol. Bull., 126: 844-872.

Rintala, D.H., C.A. Howland, M.A. Nosek, J.L. Bennett and M.E. Young et al., 1997. Dating issues for women with physical disabilities. Sexuality Disability, 15: 219-242.

Roscoe, B., M.S. Diana and R.H. Brooks, 1987. Early, middle and late adolescents' views on dating and factors influencing partner selection. Adolescence, 85: 59-68.

Rose, S.M. and I.H. Frieze, 1993. Young singles' contemporary dating scripts. Sex Roles, 28: 499-509. DOI: $10.1007 / \mathrm{BF} 00289677$

Stepp, L.S., 2007. Unhooked: How young women pursue sex, delay love and lose at both. New York, NY: Penguin Group. 
Stevens, S.E., C.A. Steele, J.W. Jutai, I.V. Kalnins and J.A. Bortolussi et al., 1996. Adolescents with physical disabilities: Some psychosocial aspects of health. J. Adolescent Health, 19: 157-164.

Sunnafrank, M., 1986. Predicted outcome value during initial interactions: A reformulation of uncertainty reduction theory. Human Communication Res., 13: 3-33. DOI: 10.1111/j.1468-2958.1986.tb00092.x

Tepper, M.S., 2005. Becoming sexually able: Education for adolescents and young adults with disabilities. Contemporary Sexuality, 39: 1-7.

Thibaut, J.W. and H.H. Kelley, 1959. The social psychology of groups. New York: Wiley.

WHO, 1999. International classification of functioning, disability and health (ICF/ICIDH). Encyclopedia of Disability, Beta-2 draft (Full Version), World Health Organization.

\section{Appendix}

\section{Scenario 1}

\section{Attractive, Active, in Wheelchair}

It is Friday night. You decide to go to a small local bar to hang out and meet new people. As you walk through the front door, there is a long bar on the left side and tables on the right side. In the back of the bar are a few pool tables and chairs. The bar is not busy yet, so it is not difficult to move around. You walk up to the bar to order something to drink. As you are waiting for the bartender to fill your order, you look at the other people in the bar. As you scan the room, you make eye contact with an extremely attractive person of the opposite sex who is "eyeing" you (i.e., he/she appears to be looking at you with interest). This individual is seated behind the pool tables with a pool cue in one hand and what looks to be a mixed drink in the other. You look around, to see if the person is at the bar with someone. They do not seem to be with anyone in particular. You thought they were sitting in one of the bar's chairs. When they go to shoot pool, you notice that they are not in a chair, but in a wheelchair. They glance over at you once more after their shot.

\section{Scenario 2}

\section{Active, in Wheelchair}

It is Friday night. You decide to go to a small local bar to hang out and meet new people. As you walk through the front door, there is a long bar on the left side and tables on the right side. In the back of the bar are a few pool tables and chairs. The bar is not busy yet, so it is not difficult to move around. You walk up to the bar to order something to drink. As you are waiting for the bartender to fill your order, you look at the other people in the bar. As you scan the room, you make eye contact with someone of the opposite sex who is "eyeing" you (i.e., he/she appears to be looking at you with interest). This individual is seated behind the pool tables with a pool cue in one hand and what looks to be a mixed drink in the other. You look around, to see if the person is at the bar with someone. They do not seem to be with anyone in particular. You thought they were sitting in one of the bar's chairs. When they go to shoot pool, you notice that they are not in a chair, but in a wheelchair. They glance over at you once more after their shot.

\section{Scenario 3}

\section{No Activity, Attractive Wheelchair}

It is Friday night. You decide to go to a small local bar to hang out and meet new people. As you walk through the front door, there is a long bar on the left side and tables on the right side. In the back of the bar are a few pool tables and chairs. The bar is not busy yet, so it is not difficult to move around. You walk up to the bar to order something to drink. As you are waiting for the bartender to fill your order, you look at the other people in the bar. As you scan the room, you make eye contact with an extremely attractive person of the opposite sex who is "eyeing" you (i.e., he/she appears to be looking at you with interest). This individual is seated behind the pool tables with what looks to be a mixed drink in their hand. You look around, to see if the person is at the bar with someone. They do not seem to be with anyone in particular. You thought they were sitting in one of the bar's chairs. When they move to put their drink down, you notice that they are not in a chair, but in a wheelchair. They glance over at you once more.

\section{Scenario 4}

\section{No Activity, Wheelchair}

It is Friday night. You decide to go to a small local bar to hang out and meet new people. As you walk through the front door, there is a long bar on the left side and tables on the right side. In the back of the bar are a few pool tables and chairs. The bar is not busy yet, so it is not difficult to move around. You walk up to the bar to order something to drink. As you are waiting for the bartender to fill your order, you look at the other people in the bar. As you scan the room, you make eye contact with someone who is "eyeing" you (i.e., he/she appears to be looking at you with interest). This individual is seated behind the pool tables with a mixed drink in their hand. You look around, to see if the person is at the bar with someone. They do not seem to be with anyone in particular. You thought they were sitting in one of the 
bar's chairs. When they move to put their drink down, you notice that they are not in a chair, but in a wheelchair. They glance over at you once more.

\section{Scenario 5}

\section{Attractive, Active, Able Bodied}

It is Friday night. You decide to go to a small local bar to hang out and meet new people. As you walk through the front door, there is a long bar on the left side and tables on the right side. In the back of the bar are a few pool tables and chairs. The bar is not busy yet, so it is not difficult to move around. You walk up to the bar to order something to drink. As you are waiting for the bartender to fill your order, you look at the other people in the bar. As you scan the room, you make eye contact with an extremely attractive person of the opposite sex who is "eyeing" you (i.e., he/she appears to be looking at you with interest). This individual is seated behind the pool tables with a pool cue in one hand and what looks to be a mixed drink in the other. You look around, to see if the person is at the bar with someone. They do not seem to be with anyone in particular. They walk to the pool table to shoot pool. They glance over at you once more after their shot.

\section{Scenario 6}

\section{Active, Able Bodied}

It is Friday night. You decide to go to a small local bar to hang out and meet new people. As you walk through the front door, there is a long bar on the left side and tables on the right side. In the back of the bar are a few pool tables and chairs. The bar is not busy yet, so it is not difficult to move around. You walk up to the bar to order something to drink. As you are waiting for the bartender to fill your order, you look at the other people in the bar. As you scan the room, you make eye contact with someone of the opposite sex who is "eyeing" you (i.e., he/she appears to be looking at you with interest). This individual is seated behind the pool tables with a pool cue in one hand and what looks to be a mixed drink in the other. You look around, to see if the person is at the bar with someone. They do not seem to be with anyone in particular. They walk to the pool table to shoot pool. They glance over at you once more after their shot.

\section{Scenario 7}

\section{No Activity, Attractive Able Bodied}

It is Friday night. You decide to go to a small local bar to hang out and meet new people. As you walk through the front door, there is a long bar on the left side and tables on the right side. In the back of the bar are a few pool tables and chairs. The bar is not busy yet, so it is not difficult to move around. You walk up to the bar to order something to drink. As you are waiting for the bartender to fill your order, you look at the other people in the bar. As you scan the room, you make eye contact with an extremely attractive person of the opposite sex who is "eyeing" you (i.e., he/she appears to be looking at you with interest). This individual is seated behind the pool tables with what looks to be a mixed drink in their hand. You look around, to see if the person is at the bar with someone. They do not seem to be with anyone in particular. They glance over at you once more.

\section{Scenario 8}

\section{No Activity, Able Bodied}

It is Friday night. You decide to go to a small local bar to hang out and meet new people. As you walk through the front door, there is a long bar on the left side and tables on the right side. In the back of the bar are a few pool tables and chairs. The bar is not busy yet, so it is not difficult to move around. You walk up to the bar to order something to drink. As you are waiting for the bartender to fill your order, you look at the other people in the bar. As you scan the room, you make eye contact with someone of the opposite sex who is "eyeing" you (i.e., he/she appears to be looking at you with interest). This individual is seated behind the pool tables with a mixed drink in their hand. You look around, to see if the person is at the bar with someone. They do not seem to be with anyone in particular. They glance over at you once more. 